\title{
Effects of Open Boundary Location on the Far-Field Hydrodynamics of a Severn Barrage
}

\author{
Juntao Zhou*, Shunqi Pan and Roger A. Falconer \\ Hydro-environmental Research Centre, School of Engineering, \\ Cardiff University, Cardiff CF24 3AA, UK
}

\section{Abstract}

The Severn Estuary has the second largest tide range in the world and a barrage across the estuary from Cardiff in South Wales to Weston in South West England has been proposed for over half a century, to extract large amounts of tidal energy from the estuary. To assess the environmental impacts of the proposed tidal barrage requires accurate model predictions of both the near-field and far-field hydrodynamics, which can strongly depend on the model area and the appropriate boundary forcing. In this paper two models, based on the Environmental Fluid Dynamics Code (EFDC) numerical model with a recently-developed Barrage module (EFDC_B), were set up with different computational domains. The Continental Shelf model, which was centred on the Bristol Channel, has its open boundary extended to beyond the Continental Shelf. The Irish Sea model, which was also centred around the Bristol Channel, only has its open boundary extended to the Celtic Sea in the south and the Irish Sea in the north. In order to investigate the effects of the open boundary conditions imposed in the models on the near and far-field hydrodynamics, for the case of the Severn Barrage, the Continental Shelf model was first run with and without the operation of the Severn Barrage. The Irish Sea model was then run, also with and without the operation of the Severn Barrage, and with the open boundary conditions provided by the Continental Shelf model. The results from both models were then analysed to study the impact of the tidal barrage on the near-field and far-field hydrodynamics in the Bristol Channel and Irish Sea. Detailed comparisons of the model results indicate that the hydrodynamic conditions along the open boundaries of the Irish Sea model are affected by the tidal barrage and that the open boundary conditions also have noticeable impacts on the far-field hydrodynamics, especially in the Irish Sea, with approximately an average 4-7 cm difference in the maximum water levels predicted in Cardigan Bay and with a maximum difference of $9 \mathrm{~cm}$ in the northern part of Cardigan Bay.

Key words: boundary conditions, Continental Shelf model, Irish Sea model, Severn Barrage, EFDC_B model, far-field impact

\section{Introduction}

With the second highest tidal range in the world, the Bristol Channel and Severn Estuary, located in the southwest of the UK, is regarded as an ideal site for potential extraction of tidal energy. Amongst a number of design locations for a tidal barrage scheme, the Severn Barrage proposed between Cardiff in Wales and Weston in South West England is the most studied scheme, with Fig. 1 showing the location of the project site.

Tidal barrages in the Severn Estuary have been studied for nearly a century, but particularly in detail over the past 30 years. It has previously been normal practice that the numerical models used to study a barrage impact are first calibrated to reproduce the natural tidal regime (without any structures) and then re-run with the structures in place to study the impact of the structure by comparing the model results (Prandle, 1980; Garrett and Greenberg, 1977; Adcock et al. 2011). In most of these studies the same open boundary conditions have been used, hence as a result, any changes

* Corresponding author. Address: Hydro-environmental Research Centre, School of Engineering, Cardiff University, Cardiff CF24 3AA, UK. Tel.:+44 (0) 292087 6814. E-mail address: juntaozhou@gmail.com. 
of the tidal dynamics due to a tidal barrage along the open boundaries may have been ignored. More recently, Ahmadian et al. (2010) used the DIVAST model to investigate the impacts of the Severn Barrage on the hydrodynamics and corresponding transport processes of suspended sediments and faecal bacteria in the Bristol Channel and Severn Estuary. Likewise, Xia et al. (2010a, 2010b, 2010c) employed a 2D finite volume numerical model to investigate the impact on the hydrodynamic processes based on different barrage operative schemes. The impacts of the Severn Barrage on the hydrodynamic and salinity transport processes were also predicted by Zhou et al. (2014) using the EFDC_B model. In these studies, the research interests mainly focused on the near-field impacts from a tidal barrage.

However, due to the large tidal range in the Severn Estuary and the large water body enclosed by the barrage, the impact of the barrage on the near-field and far-field hydrodynamics can be equally important, particularly for environmental and flood risk assessments. Key issues when modelling the effects of a tidal barrage in such context are consideration of the computational domain and, in particular, the influence of the imposed open boundary conditions and the influence that a barrage might have on these boundaries. Bondi et al. (1981) used several models to calculate the full tidal response of the barrage, some of which extended their computational domains outside the Bristol Channel and included the Irish Sea, the English Channel and parts of the Continental Shelf. However, significant discrepancies were found in the predicted results of these computer models. As recently pointed out by Rainey (2009), any model that simply held the boundary condition fixed at the model boundary at the same value with a barrage would be likely to reduce the model accuracy and cause gross discrepancies in the model predictions. In particular, for studies related to a tidal barrage in the Severn Estuary, this assumption could be particularly inappropriate, as the disturbance in the tidal regime introduced by a tidal barrage can propagate far from the barrage site and can affect the open boundary conditions of the model if the computational domain is not sufficiently large. It is also suggested that the high tidal range in the Severn Estuary is the result of the size of the estuary being close to resonance with the continental shelf, coupled with the funnel shaped geometry of the channel (Bondi, 1981; Pugh, 1987). Hence, the location of the open boundaries of a modelling system for this estuary can be particularly important in determining the accuracy of the model results. The open boundary problem and some corresponding mitigation strategies were discussed in Adcock et al. (2011). One of the mitigation strategies with effective numerical implementation was to extend the computational domain beyond the edge of the continental shelf. Since the water depth beyond the continental shelf is much larger than that on the shelf, the outgoing waves from the shelf towards the deep ocean will tend to be reflected back on to the shelf (with a $180^{\circ}$ phase shift) rather than being transmitted due to the sudden changes of water depth. This reflection explains why large tides occur when the continental shelf is a quarter wave-length from the land, as exactly the same resonant condition takes place for waves reflected off a rapid change in water depth as happens at the edge of the continental shelf. This is the principal cause of the large tides in the Bristol Channel (Owen, 1980). Hence in order to accurately assess the impacts of the tidal barrage, the open boundaries of the model need to be extended to beyond the edge of the continental shelf to capture the change to this resonance due to the inclusion of a tidal barrage. Whilst Adcock et al. (2011) addressed the open boundary problem theoretically, this paper gives a detailed quantitative analysis of the effects caused by different open boundary locations and conditions when simulating the impact of the Severn Barrage.

In this paper, the EFDC_B model (Zhou et al., 2014) i.e. the modified EFDC model with the barrage module, was used to set up two model domains to carry out a detailed investigation into the effects of the open boundary on the far-field hydrodynamics for the case of the Severn Barrage. The Continental Shelf model (refereed to as the CS model hereinafter) was centred around the Bristol Channel with its open boundary being extended to beyond the Continental Shelf. The Irish Sea model (refereed to as the IS model hereinafter) was also centred around the Bristol Channel, but 
with its open boundary only being extended to include the Celtic Sea in the south and the Irish Sea in the north. The CS model was first run with and without the operation of the Severn Barrage. Then the IS model was also run with and without the operation of the Severn Barrage, with the results from the Continental Shelf model being used to provide the open boundary conditions for the Irish Sea model. The model results from both models were then compared in a detailed analysis of the impacts of the Severn Barrage on the near-field and far-field hydrodynamics in the Bristol Channel and Irish Sea when the different computational domains were used. The details of the model are given in Section 2, with Section 3 detailing of the model setup and computational domains, followed by the model validation given in Section 4. The effects of the open boundary are presented in Section 5, followed by further discussion and conclusions.

\section{Model Description}

The EFDC model (Hamrick, 1992) is a general purpose modelling package for simulating three-dimensional hydrodynamic, solute, and biogeochemical processes in surface water systems, including: rivers, lakes, estuaries, reservoirs, wetlands and near-shore to shelf-scale coastal regions. The EFDC model can predict water levels and velocity components, salinity and temperature distributions and also the processes of cohesive and non-cohesive sediment transport, near field and far field discharge dilutions from multiple sources, eutrophication, the transport and fate of toxic contaminants in the water and sediment phases, and the transport and fate of various life stages of finfish and shellfish. The EFDC model also simulates drying and wetting in shallow areas, using a mass conservative scheme. Various flow control structures, such as weirs, spillways and culverts can also be simulated in the model.

The model uses either stretched or sigma vertical coordinates and Cartesian or curvilinear orthogonal horizontal coordinates. Dynamically coupled transport equations for turbulent kinetic energy, turbulent length scale, salinity and temperature are also included. The two turbulence parameter transport equations based on the Mellor-Yamada level 2.5 turbulence closure schemes are used (Mellor and Yamada, 1982). A second-order accurate spatial finite difference formulation on a staggered (or C) grid is used to solve the momentum equations, while a second-order accurate threetime level finite difference scheme is used, with an internal-external mode splitting procedure adopted to separate the internal shear, or baroclinic mode, from the external free surface gravity wave, or barotropic mode. A numerical solution based on a second-order accurate scheme, in both space and time, and a mass conservative fractional step algorithm is used to solve the transport equations for salinity, temperature and other constituents. More details of the governing equations for the original EFDC hydrodynamic model equations and the numerical schemes can be found in Hamrick (1992). The EFDC model is public domain software, and has been extensively tested and applied to more than 100 modelling studies worldwide. The model has been successfully applied to reservoirs and lakes (Khangaonkar et al. 2005), and to bays and estuaries (Yang and Hamrick, 2003; Cerco et al. 2010; Liu and Huang, 2009; Shen et al. 1999) to study the hydrodynamic processes and water quality (Zou et al. 2006), tidal intrusion and sediment transport and its impact on the fate of faecal bacteria (Bai and Lung, 2005).

In this study, the main aim has been to assess numerically the impact of the proposed Severn Barrage on the near-field and far-field hydro-environment parameters in the Severn Estuary, Bristol Channel and the Irish Sea. Hence a barrage module has been developed and implemented within the EFDC model to represent the operation of a barrage. Whilst the details of the EFDC_B have been given in Zhou et al. (2014), for completeness a brief description of the barrage module is given herein. There are two main types of devices frequently included in barrages for connecting the conditions upstream and downstream of the structure, i.e. sluice gates and turbines. The numerical implementation of a sluice gate is generally similar to the procedure that occurs in reality. When the sluice gates need to be closed, then the 
current velocities through the computational cells representing the sluice gates are set to gradually decrease to zero. Likewise when the sluice gates need opening, the velocities are set to increase gradually to their peak velocity. Hydraulic structures have been adopted to represent the discharge through turbines. The upstream and downstream flow conditions of the hydraulic structure have been linked dynamically using a $Q-H$ relationship, generally acquired from field or experimental data. In the absence of a $Q-H$ relationship the discharge $Q$ through a turbine was obtained by linking $Q$ with the head difference between the upstream and downstream water levels as given by:

$Q=C_{d} A \sqrt{2 g H}$

where $C_{d}$ is the discharge coefficient of a turbine; $A$ is the mean flow-through area of the turbine and $H$ is the water level difference across the turbine.

For the original Severn Barrage Severn Tidal Power Group (STPG) study (1989), the turbine diameter was proposed to be $9 \mathrm{~m}$, and the mean flow-through area of each turbine, i.e. $A$, was $63.6 \mathrm{~m}^{2}$. The formula for computing the generation power $P$ was expressed as:

$$
P=\rho g Q H \eta
$$

where $\rho$ is the specific density of sea water; and Q is the discharge across the turbines; $\eta$ is the efficiency coefficient of the turbines and $g$ is gravitational acceleration. In the current study, both the discharge coefficient $C_{d}$ for the turbines and the efficiency coefficient $\eta$ were assumed to be 1.0 as suggested by Baker (2006) and Xia et al. (2010b).

The other hydraulic structures such as the ship locks, sub-stations and embankments along the barrage line were all treated as wall boundaries. When the barrage module was activated, the instant opening and closing of the turbines and the sluice gates were observed to cause numerical oscillations in water elevations. To eliminate these numerical oscillations, a ramp function was introduced to change the flow volume through the turbines and sluice gates during the opening and closing of turbines and sluice gates, as would occur in reality. The ramp function is expressed in the form of a half sinusoidal function as: $f=\sin \left(\frac{\pi}{2 T} t\right), 0<t \leq T$, where $T$ is the ramping period, set to 10 minutes in the present study based on the typical opening times cited in the literature for commercial turbines, and $t$ is time. When the turbine valves (or sluice gates) start to open, $t=0$ and $f=0$, and when they are fully opened, $t=T$ and $f=1$. Likewise, when these hydraulic structures need closing, the ramp function is changed into a half cosine function giving: $f=\cos \left(\frac{\pi}{2 T} t\right), 0<t \leq T$. Based on the different operational procedures of the barrage and the head differences downstream and upstream of the barrage, these can be used to decide when to open or close the turbine valves and sluice gates, and then the flow volume through the turbines and sluice gates are gradually increased or decreased by multiplying the discharges by the ramp function.

The Severn Barrage scheme proposed by the Severn Tidal Power Group (1989) stretched nearly 16 km from Lavernock Point, just southwest of Cardiff, to southwest of Brean Down, near Weston-Super-Mare. This scheme included 216 bulb turbines and 166 sluices. The energy operating scheme for this original Severn Barrage layout was designed as a oneway generation process, i.e. ebb-only generation. An ebb-only generation scheme usually has four modes of operation, including: filling, holding (i), generating, and holding (ii), respectively. When the barrage is at the filling stage, the sea 
water flows through the sluices and turbines, raising the water level upstream of the barrage until high water level is reached and then the sluice gates and turbines are closed. For the holding stage (i): both the turbines and sluice gates are kept closed until there is a sufficient head difference (i.e. the starting head) created between the upstream and downstream sides of the barrage due to the sea level fall, the turbines are then opened and flow is permitted through the barrage, generating power until the head difference is lower than the minimum water head required for turbine operation. At the last stage, i.e. the holding stage (ii), both the turbines and sluice gates are closed again until the downstream sea water level is greater than the basin level, and another filling stage then commences.

\section{Model Setup}

Using the same EFDC_B code, two models with different computational domains were set up to investigate the effects of the open boundary conditions on the predicted hydrodynamic results and particularly the water elevations. Both models were centred around the Severn Estuary; the computational domain of the CS model extended to beyond the edge of the continental shelf, as shown in Fig. 1, while the computational domain of IS model covered part of the Celtic Sea and the entire Irish Sea, which is also shown in Fig. 1 as indicated by the dashed-lines.

The boundaries of the CS model were: the southern boundary, which was between point (45N, $12 \mathrm{~W})$ and point (45N, $1.3 \mathrm{~W})$, the western boundary, between points $(45 \mathrm{~N}, 12 \mathrm{~W})$ and $(56.5 \mathrm{~N}, 11 \mathrm{~W})$ via points $(48 \mathrm{~N}, 14 \mathrm{~W})$ and $(52 \mathrm{~N}, 16 \mathrm{~W})$, the eastern boundary, between points $(48.87 \mathrm{~N}, 3.5 \mathrm{~W})$ and $(50.25 \mathrm{~N}, 3.5 \mathrm{~W})$ and the northern boundary, between points $(56.5 \mathrm{~N}, 11 \mathrm{~W})$ and $(56.73 \mathrm{~N}, 6.24 \mathrm{~W})$. The computational domain covered a total plan surface area of $846,800 \mathrm{~km}^{2}$ at mean tidal level, and was represented by 258, 824 cells. The eastern and northern boundaries were mainly the land boundary of the west coastline of the UK and part of the English Channel. In this model there were significant changes in the bathymetry throughout the entire domain, with the bed level varying from more than 5,000 m below Ordnance Datum at the westernmost boundaries, beyond the Continental Shelf, to $5 \mathrm{~m}$ above Ordnance Datum, around the easternmost landward boundary close to Gloucester, resulting in dramatic changes in the water depth. The water depth in the Irish Sea area ranges from between $50 \mathrm{~m}$ to $100 \mathrm{~m}$, and it varies gradually from $60 \mathrm{~m}$ to less than $10 \mathrm{~m}$ between the seaward end of the Bristol Channel and the Severn Estuary. These depth variations exhibit very steep gradients of the seabed levels. In addition, the surface width from west to east also decreases significantly.

Under natural conditions, the sea water flows from the wide open sea into the Irish Sea primarily via a $77 \mathrm{~km}$ narrow channel, and into the Bristol Channel through a $72 \mathrm{~km}$ strait. Therefore, when a large influx of sea water enters the Irish Sea and Bristol Channel, hydrodynamic processes in these areas become rather complex. Taking into account the irregular land boundary in the Irish Sea and in the Bristol Channel, and the high tidal range in the Severn Estuary, it has always been a challenging task to calibrate numerical models in this region. Model calibrations in this study are focused on comparing the computed and measured tidal levels and currents at a large number of locations throughout the computational domain.

The computational domain of the IS model was nested within the CS model, as indicated in Fig. 1: the western boundary was between points $(48.5 \mathrm{~N}, 10 \mathrm{~W})$ and $(56.73 \mathrm{~N}, 10 \mathrm{~W})$, and the southern boundary between points (48.5N, $10 \mathrm{~W})$ and $(48.5 \mathrm{~N}, 4.83 \mathrm{~W})$. The model covered a plan surface area of $267,600 \mathrm{~km}^{2}$ and was represented by 199,517 cells.

For accurate simulations of the barrage operating scheme and the complex flow patterns around the barrage, the grid was locally refined in the region surrounding the barrage to improve the representation of the barrage structure, and for accuracy and compatibility, both models used similar grid resolutions in the near-shore areas. Typical cell sizes in the 
regions downstream and upstream of the barrage, the outer region of the Bristol Channel and the Irish Sea region were $120 \mathrm{~m}, 500 \mathrm{~m}$ and $1,000 \mathrm{~m}$ respectively. In order to obtain the same computational accuracy between the cases both with and without the barrage, the same mesh was used for both cases, except in the region of the barrage. Based on earlier sensitivity analyses, for both models, a time step of $5 \mathrm{~s}$ was used for simulations with and without a barrage. The total CPU time for each 14 days of simulation for the CS and IS models was 20 hours and 18 hours respectively on a desktop PC.

There are two types of hydrodynamic open boundary conditions adopted in EFDC model. The first type uses the standard specification of water surface elevations, using combinations of harmonic constituents and time series. The second type uses the radiation-separation boundary condition. With this type of boundary condition, the incoming wave at an open boundary is separated from the outgoing wave and the incident wave is assumed to be twice the surface elevation required. By default, the outgoing characteristic is left undefined, allowing waves generated interior to the model domain to pass outward across the boundary with no reflection. In this study, the first type of boundary condition was used, with all seawards boundaries being treated as open boundaries and with water levels being specified. For the CS model, water levels along the open boundaries were extracted from the MIKE21 global model, DHI software (2007). For the sake of brevity, the case without a barrage simulated by the CS model is referred to as C1, and the case with a barrage is referred to as C2. For the simulations with the IS model, the water levels from both the C1 and C2 models were obtained at the same locations as the open boundaries of the IS model.And with these water levels then being used to drive the IS model. When the IS model is driven by the water levels extracted from C1, the case without the tidal barrage is referred to herein as I1, and the case with the tidal barrage is referred to as I2. When the IS model is driven by the water levels extracted from C2, then the case with the tidal barrage is referred to as I3. In theory, both C1 and I1 are under the natural conditions for the estuary (i.e. without the tidal barrage), with the results within the IS model domain expected to be identical. Therefore, those two cases were used as a benchmark case for inter-comparisons. Model validations were specifically carried out for C1 and I1 to ensure model accuracy. For the same reasons, the results of $\mathrm{C} 2$ and $\mathrm{I} 3$ were also expected to be the same.

\section{Model Validations}

Both CS and IS models were run for 14 days, from $1^{\text {st }}$ to $14^{\text {th }}$ March 2005, over a neap-spring tidal cycle. The computed tidal levels were compared with the observed tidal levels at 6 tidal locations. The locations included tidal gauge stations in the Severn Estuary (Newport), the Bristol Channel (Hinkley Point), the Irish Sea (Llandudno and Workington), and two stations in the Celtic Sea (Newlyn and Milford Haven). All of these locations are indicated in Fig. 1 by triangles. Fig. 2 shows comparisons of the tidal levels between $6^{\text {th }}$ and $13^{\text {th }}$ March 2005, at all six locations, as described previously for the computed water levels from both the CS and IS models and against the measured tidal levels obtained from UK tide gauge network. The results indicate good agreement at all locations. The tidal levels computed by both the CS and IS models match well in terms of both magnitudes and phases. However, close examination of the water level at the Llandudno and Workington stations reveals that both models under-predict the peak tidal levels at these sites by approximately $30 \mathrm{~cm}$ to $50 \mathrm{~cm}$ during large spring tides, this discrepancy is thought to be due to the complex geometry surrounding these locations, but nevertheless such discrepancies generally only occur when the tidal range is more than $8 \mathrm{~m}$. The computed tidal currents have been validated against the tidal stream data given in the Admiralty Charts 1121, 1123 and 2649. Again, six locations throughout the IS model computational domain were selected for model validation, as also shown in Fig. 1 (indicated by circles). The tidal stream was reconstructed for 6 hours at either side of high water slack tide. Because similar comparisons can be observed at the six locations, only one comparison at 
location W is presented here. Fig. 3 shows comparisons of the computed tidal current speeds and directions from the CS and IS models against the tidal stream reconstructed from the Admiralty Charts. Once again the comparisons show good agreement between the model predictions and the chart data.

It is also found that the tidal phase difference at Newport can be about 25 min, which may be due to the difference of measured location and that where the model results were taken. However, the RMS water level differences at all 6 locations, as listed in Table 1, are small, indicating that the model predictions agree well with the measurements and, the IS model generally gives better predictions. The RMS values for the predicted and observed current velocities are listed in Table 2, which again indicates a good level of agreement.

Table 1 RMS values for the differences of predicted and measured tidal elevations (units: m)

\begin{tabular}{|c|c|c|c|c|c|c|}
\hline Location & Newport & Hinkley Point & Milford & Newlyn & Llandudno & Workington \\
\hline RMS (CS) & 0.3654 & 0.3446 & 0.2182 & 0.1655 & 0.2317 & 0.3566 \\
\hline RMS (IS) & 0.3598 & 0.3396 & 0.2053 & 0.1703 & 0.1975 & 0.3391 \\
\hline
\end{tabular}

Table 2 RMS values for the difference of predicted and measured current speeds (units: m/s)

\begin{tabular}{|c|c|c|c|c|c|c|}
\hline Location & Site B & Site F & Site Q & Site W & Site Y & Site P \\
\hline RMS (CS) & 0.1512 & 0.1193 & 0.1492 & 0.2270 & 0.2342 & 0.3306 \\
\hline RMS (IS) & 0.1920 & 0.1247 & 0.1819 & 0.1888 & 0.2549 & 0.3334 \\
\hline
\end{tabular}

In general, the comparisons of the computed water levels and tidal currents with the field data show that both models can provide reliable predictions for the natural conditions and the use of the DHI boundary conditions for the CS model is satisfactory.

\section{Effects of the open boundary}

After validating both the CS and IS models, the effects of the open boundary on both the far-field and near-field hydrodynamics were examined, mainly in terms of the maximum water levels and tidal currents, from the IS model. First, the CS model was run without and with the inclusion and operation of the Severn Barrage, driven by the same tidal conditions along its open boundaries. Due to the extended size of the computational domain, it was assumed for these cases that the effects of the barrage on the open boundaries of the CS model were minimal. Likewise, the difference in the maximum tidal levels between the two cases was calculated by subtracting the maximum tidal levels of the case without the barrage from the case with the barrage. Fig. 4 shows the differences in the maximum water levels during a spring tide between Cases C1 (without the barrage) and C2 (with the barrage). It can be seen from Fig. 4 that the maximum water level differences upstream and downstream of the barrage were predicted to be reduced by about $50 \mathrm{~cm}$ and $20 \mathrm{~cm}$, respectively. The differences in the maximum water levels in the regions of Swansea Bay, Carmarthen Bay and in the middle of Bristol Channel were about $15 \mathrm{~cm}, 19 \mathrm{~cm}$ and $12 \mathrm{~cm}$ respectively. For most of the Irish Sea region, the maximum water levels increased, especially in the Cardigan Bay region, by about 5 to $9 \mathrm{~cm}$. 
However, in other areas of the computational domain, the change in the maximum water levels associated with the operation of the barrage was insignificant. For the purpose of easier comparisons between the CS and IS model results, only the same area as the IS model is presented in Fig. 4. These results, as shown in Fig. 4, indicate that because of the obstruction of the barrage, the volume of water flowing into the Bristol Channel would be reduced significantly, which would force more water to flow into the Irish Sea and change the resonance frequency of the Bristol Channel and Severn Estuary basin. The change in the water levels in the Bristol Channel and Severn Estuary also affects the tidal currents in the Bristol Channel.

Secondly, the tidal levels along the open boundaries of the IS model were extracted from C1, providing the boundary conditions for the IS model. Then the IS model was run for I1 and I2. Fig. 5 shows the difference in the maximum water levels between I1 and I2.

If it is assumed that there was no open boundary effect, one would expect the results shown in Figs. 4 and 5 to be nearly identical. However, they markedly differ. Significant differences in the water levels can be found in the areas in the Cardigan Bay and the eastern Irish Sea, including Liverpool Bay. This confirms that the open boundary conditions have a profound impact on the predicted far-field hydrodynamics due to the operation of the Severn Barrage, which can be attributed to the change in the tidal dynamics of the domain due to the construction of the barrage. In Fig. 4, it can be seen that the maximum water levels at the near field (i.e. the Severn Estuary) and the far field (i.e. Cardigan Bay and Liverpool Bay) are both affected. However, in Fig. 5, the maximum water levels affected are limited to the near field regions, and the impacts of the barrage at the far field are significantly reduced. The results clearly indicate the significance of the open boundary effects on the tidal level predictions. Simply using the extracted tidal levels from the C1 model set-up along the IS model boundaries for the case with the barrage is inadequate to reproduce accurately the impacts of the barrage, particularly when studying the far-field effects. Therefore, it becomes particularly important to quantify these impacts should this model operation be the only option.

To verify the differences established from Figs. 4 and 5, the IS model was also run for the barrage operation using the boundary conditions extracted from the C2 set-up, namely I3. The differences in the maximum water levels between I1 and I3 are illustrated in Fig. 6. Comparing Figs. 4 and 6, it can be concluded that they are almost identical, except in the Carmarthen Bay region where the water level differences of approximately $2 \mathrm{~cm}$ are noted. The results indicate that the IS model is well validated and capable of reproducing the hydrodynamics accurately in the area if proper open boundary conditions are imposed.

In order to gain some insights into the effects of the tidal barrage on the open boundaries of the IS model, three points along the western and southern boundaries of the IS model (i.e. P1, P2 and P3 as shown in Fig. 1) are first chosen for further analysis. In Fig. 7, the difference in the tidal levels between C1 and C2 are plotted alongside, with the tidal level time series (dashed line) to indicate the tidal stage. For brevity, the water levels presented by the dashed lines in Figs. 710 were obtained from C1. Fig. 7 shows that the maximum water levels at these three points are similar just below 2 m, but the water level differences are found to exhibit different patterns. At P1, which is located at the northern part of the western open boundary of the IS model, the water level differences are very small, being typically less than $1 \mathrm{~cm}$ over 4 tidal cycles. A similar pattern can also be seen at P3, which is located at the southern open boundary of the IS model. However, at P2, which is located at the southern part of the western open boundary of the IS model, the differences are considerably greater than those at P1 and P3. Within a tidal cycle, the maximum water level differences occur shortly after the mean water level during both the flood and ebb phases, but do not coincide with the high water levels. It can also be found that the water level differences vary in high frequency, similar to M4 tides. The results indicate that the 
reflected tidal waves from the barrage can propagate over a very long distance in the area, and the open boundaries normal to the tidal wave propagating path can be significantly affected (at P2), while the impacts at the other locations are much less significant (i.e. at P1 and P3).

\section{Discussion}

To study further the impact of the tidal barrage on both the near-field and far-field hydrodynamics in the model area, 5 additional locations throughout the IS model computational domain were selected, i.e. P4, P5, P6, P7 and P8 as illustrated in Fig. 1 by triangles. P4 and P5 are located near the entrance to the Bristol Channel and in the middle of the Bristol Channel respectively, and P6 is located at the northern corner of Cardigan Bay, whilst P7 and P8 are located in Liverpool Bay and the Solway Firth, respectively. These locations provide good coverage of the entire computational domain. Further discussion will be focused on Cases C1 and C2, and Cases I1 and I2 respectively.

\subsection{Impact of the tidal barrage on water levels}

Fig. 8 shows the time series of the predicted water level differences between C1 and C2, and I1 and I2 at P4 and P5, together with the tidal level from C1. As both P4 and P5 are located in the Bristol Channel, the results at these locations are used for investigating the near-field effects. As shown in Fig. 8, the tidal range at P4 is just over $8 \mathrm{~m}$ and that at P5 is more than $10 \mathrm{~m}$. The predicted water level increase by the CS and IS models are very similar, with the former being slightly larger than the latter, but the maximum increase in the water level of is up to $20 \mathrm{~cm}$ at P4, and $81 \mathrm{~cm}$ at P5 as P5 is located closer to the barrage site. Although the results show that the maximum water level increase occurs after mean water level during the flood phase for each tidal cycle, unlike the results shown in Fig. 7 for P2, at the peak tidal levels, the water level will further increase due to the tidal barrage. Therefore, the overall impact of the barrage on the peak water level can be significant, particularly at P5, which is also illustrated in Fig. 4. However, due to the negligible differences of the water levels predicted by the CS and IS models, it is clear that the effects of the open boundary conditions (imposed for the IS model) are insignificant on the near-field water level predictions and the impacts of the barrage are dominated.

Fig. 9 shows the time series of predicted water level differences between C1 and C2, and I1 and I2, at P6, P7 and P8, which are located in Cardigan Bay, Liverpool Bay and the Solway Firth respectively, together with the tidal levels from C1. These locations were specifically chosen for studying the far-field impacts as they are progressively farther away from the barrage site. The tide ranges at these locations are between $7 \mathrm{~m}$ and $8 \mathrm{~m}$. The results show that the maximum increase in the water levels at these locations is around $10 \mathrm{~cm}$, with the largest increase being predicted in the Cardigan Bay. However, the water level differences predicted by the CS model (i.e. C1 and C2) and the IS model (i.e. I1 and I2) are found to be noticeably different at these locations. At P6 in the Cardigan Bay, the tidal wave forms are found to have a particular character, with steeper crests and flatter troughs, apparently due to the nonlinearity in the tidal wave in the shallow waters (approximately $10-15 \mathrm{~m}$ on average). In addition to the water level differences predicted by both models, the results also show a distinguishing feature of a double peak during the flood phase at this location, but they are not in-line with each other, indicating a phase difference of the tidal waves. The maximum increase in the water level predicted with the CS model coincides with high tide, which will increase the impacts of the barrage on the overall maximum water level. On the other hand, the maximum water level difference predicted by the IS model occurs prior to the high tide level. This explains the noticeable increase in the maximum water levels in Cardigan Bay due to the construction of the barrage, as shown in Fig. 4 from the CS model, but not shown in Fig. 5 from the IS model. Clearly, the impacts of the open boundary conditions on the far-field hydrodynamics became more significant in this area. 
Farther away from the barrage site, at P7 and P8, the maximum differences in the water levels are in a range of 5.5-6 cm for the CS model, and 3-5 cm for the IS model, showing the reduced impacts of the open boundary conditions in this area.

\subsection{Impact of the tidal barrage on tidal currents}

Comparisons were also made to investigate the impacts of the open boundary conditions on the tidal currents at three locations, i.e. P2, P4 and P5. As shown in Fig. 10, the tidal currents at P2, which is located at the open boundary of the IS model, are generally small, with a maximum speed of about $0.57 \mathrm{~m} / \mathrm{s}$. The differences in the tidal currents are found to be negligible at this location between $\mathrm{C} 1$ and $\mathrm{C} 2$, which means that the barrage has little impact on the tidal currents in regions of relatively large water depth. The tidal currents at P4 and P5, however, are relatively strong, with maximum speeds of $1.31 \mathrm{~m} / \mathrm{s}$ and $2.1 \mathrm{~m} / \mathrm{s}$ respectively, and the impacts from the barrage on the tidal currents are noticeable, resulting in tidal current differences being up to $0.19 \mathrm{~m} / \mathrm{s}$ and $0.52 \mathrm{~m} / \mathrm{s}$ at P4 and P5 respectively. However, the impacts from the open boundary conditions on the near-field tidal currents are found to be insignificant, as the differences between C1 and C2, and those between I1 and I2 are very similar.

While the present study uses an ebb generation scheme, the near-field and far-field hydrodynamics can also be affected by other operating schemes, such as the flood generation and two-way generation or different combinations of turbines and sluice gates. The impacts of different operating schemes in these regards are currently under further investigation.

\section{Conclusions}

In this paper, the CS and IS models were set up based on the refined EFDC_B model to investigate the effects of the open boundary conditions on the near-field and far-field hydrodynamics of a tidal barrage. Both models were first validated and calibrated with field data for water levels and current speeds. Comparisons of the predicted and measured results indicate that the two models can accurately reproduce the hydrodynamic processes in the Irish Sea, the Bristol Channel and the Severn Estuary under the natural tidal conditions.

Following validation of the models, the CS model was run with and without a tidal barrage to provide the open boundary conditions for the IS model. The results from both models were used to investigate the effects of the open boundary conditions on the predictions of the near and far-field hydrodynamics. Comparisons of the water level differences between C1 and C2 show that there are noticeable differences along the open boundaries of the IS model, and the impact can propagate through to the nested IS model, with higher order oscillations of the tidal levels generated from the tidal barrage. The boundaries directly facing the direction of the tidal wave propagation are mostly affected. The results from the CS and IS models show that the effects of the open boundary conditions are less significant on the near-field hydrodynamics, as the effects of the tidal barrage dominate in this region, but the impacts of the open boundary conditions on predicting the far-field hydrodynamics are more significant. The present study demonstrates the need to consider a large computational domain to study the far-field hydrodynamics if constructing a larger scale structure in an estuary, such as a tidal barrage, is considered. This is particularly important for sites with macro-tide conditions. This study also provides practical techniques for refined model developments to quantify these effects.

\section{ACKNOWLEGEMNTS}

This work was undertaken as part of the Low Carbon Research Institute Marine Consortium (www.lcri.org.uk) under grant number: 50194. The authors wish to acknowledge the financial support of the Welsh Government, the Higher 
Education Funding Council for Wales, the Welsh European Funding Office and the European Regional Development Fund Convergence Programme.

\section{REFERENCES}

Ahmadian, R., Falconer, RA., Lin, B., 2010. Hydro-environmental modeling of the proposed Severn barrage, Proceedings of the Institution of Civil Engineers, Energy , 163(3), 107-117.

Adcock, T. A. A, Borthwick, A. G. L, Houlsby, G. T, 2011. The open boundary problem in tidal basin modelling with energy extraction, Proceedings of EWTEC 2011, Southampton.

Bai, S., and W. S. Lung, 2005. Modeling sediment impact on the transport of fecal bacteria. Water Research. 39, 52325240.

Baker, AC., 2006. Tidal Power. The Institute of Engineering and Technology, London, 250.

Bondi, H. (chairman) and the Severn Barrage Committee 1981, Tidal power from the Severn estuary. Energy Paper No. 46. Department of Energy, Her Majesty’s Stationery Office.

Cerco, C., Tillman, D., and Hagy, JD., 2010. Coupling and comparing a spatially- and temporally-detailed eutrophication model with an ecosystem network model: An initial application to Chesapeake Bay. Environmental Modelling\& Software 25, 562-572.

DHI software, Mike 21 toolbox user guide, 2007, pp. 115-119.

Garrett, C., Greenberg, D., 1977. Predicting changes in tidal regime: the open boundary problem. Journal of Physical Oceanography, Vol. 7, No. 2, pp. 171-181.

Evans, G.P., Mollowney, B.M., Spoel, N.C., 1990. Two-dimensional Modelling of the Bristol Channel, UK. In: Spaulding, M.L. (Ed.), Proceedings of the Conference on Estuarine and Coastal Modeling. pp. 331-340.

Falconer, RA., Xia, J., Lin, B., Ahmadian, R., 2009. The Severn Barrage and other tidal energy options: hydrodynamic and power output modelling, Science in China Series E, Technological Sciences, 52 (11) 3105-3424.

Goldwag, E., Potts, R., 1989. Energy Production. In: Developments in Tidal Energy, Proceedings of the Third Conference on Tidal Power, The Institution of Civil Engineers. London: Thomas Telford, 75-92.

Hamrick, J. M., 1992: A three-dimensional environmental fluid dynamics computer code: Theoretical and computational aspects. The College of William and Mary, Virginia Institute of Marine Science, Special Report 317, 63 pp.

Khangaonkar, T., Z. Yang, C. DeGasperi, and K.Marshall. 2005. Modeling Hydrothermal Response of a Reservoir to Modifications at a High Head Dam. Water International, Volume 30, Number 3, 378-388.

Liu, X., Huang, W., 2009. Modeling sediment resuspension and transport induced by storm wind in Apalachicola Bay, USA. Environmental Modelling \& Software 24, 1302-1313.

Owen. A, 1980. The Tidal regime of the Bristol Channel: a numerical modelling approach, Geophysical Journal of the Royal Astronomical Society, vol. 62, no. 1, pp. 59-75.

Prandle, D. 1980. Modelling of tidal barrier schemes: an analysis of the open-boundary problem by reference to AC circuit theory. Estuar. Coast. Mar. Sci. 11, 53-71.

Pugh, D. T., 1987. Tides, Surges and Mean Sea-Level. John Wiley \& Sons.

Rainey, R.C., 2009. The optimum position for a tidal power barrage in the Severn Estuary. Journal of Fluid Mechanics, Vol. 636, pp. 497-507.

Severn Tidal Power Group (STPG). The Severn barrage project: general report, energy paper No. 57. London: Her Majesty’s Stationery Office (HMSO); 1989.

Shen, J., Boon, J., Kuo, A.Y., 1999. A numerical study of a tidal intrusion front and its impact on larval dispersion in 
the James River estuary, Virginia. Estuaries. 22 (3A), 681-692.

418 UK tide gauge network, available from https://www.bodc.ac.uk/data/online_delivery/ntslf/ (accessed 20 Aug 2013).

419 Xia, J., Falconer, RA., Lin, B., 2010a. Impact of different tidal renewable energy projects on the hydrodynamic processes in the Severn Estuary, UK, Ocean Modelling, 86-104.

Xia, J., Falconer, RA., Lin, B., 2010b. Impact of different operating modes for a Severn Barrage on the tidal power and flood inundation in the Severn Estuary, Applied Energy, 87 (7) 2374-2391.

Xia, J., Falconer, RA., Lin, B., 2010c. Hydrodynamic impact of a tidal barrage in the Severn Estuary, UK, Renewable Energy, 35 (7) 1455-1468.

Yang, Z., and J. M. Hamrick., 2003. Variational inverse parameter estimation in a cohesive sediment transport model: an adjoint approach. Journal of Geophysical Research, 108(C2), 3055.

427 Zhou, J., Falconer, R. A. and Lin B., 2014. Refinements to the EFDC model for predicting the hydro-environmental impacts of a barrage across the Severn Estuary. Renewable Energy, 62, pp. 490-505. 


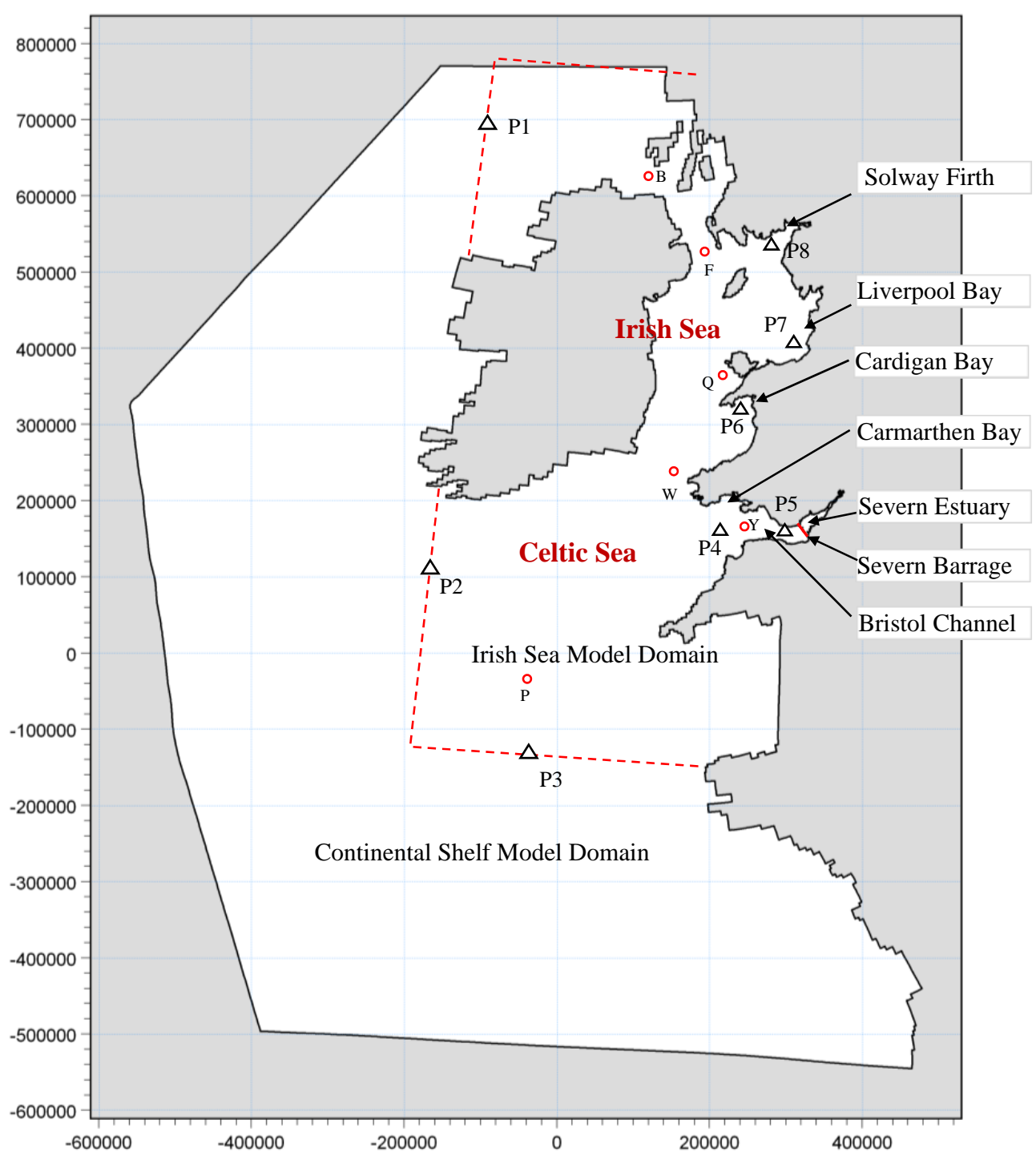

Fig. 1. Computational domains of the CS and IS models, locations for water level and tidal current comparisions and site for the Severn Barrage 

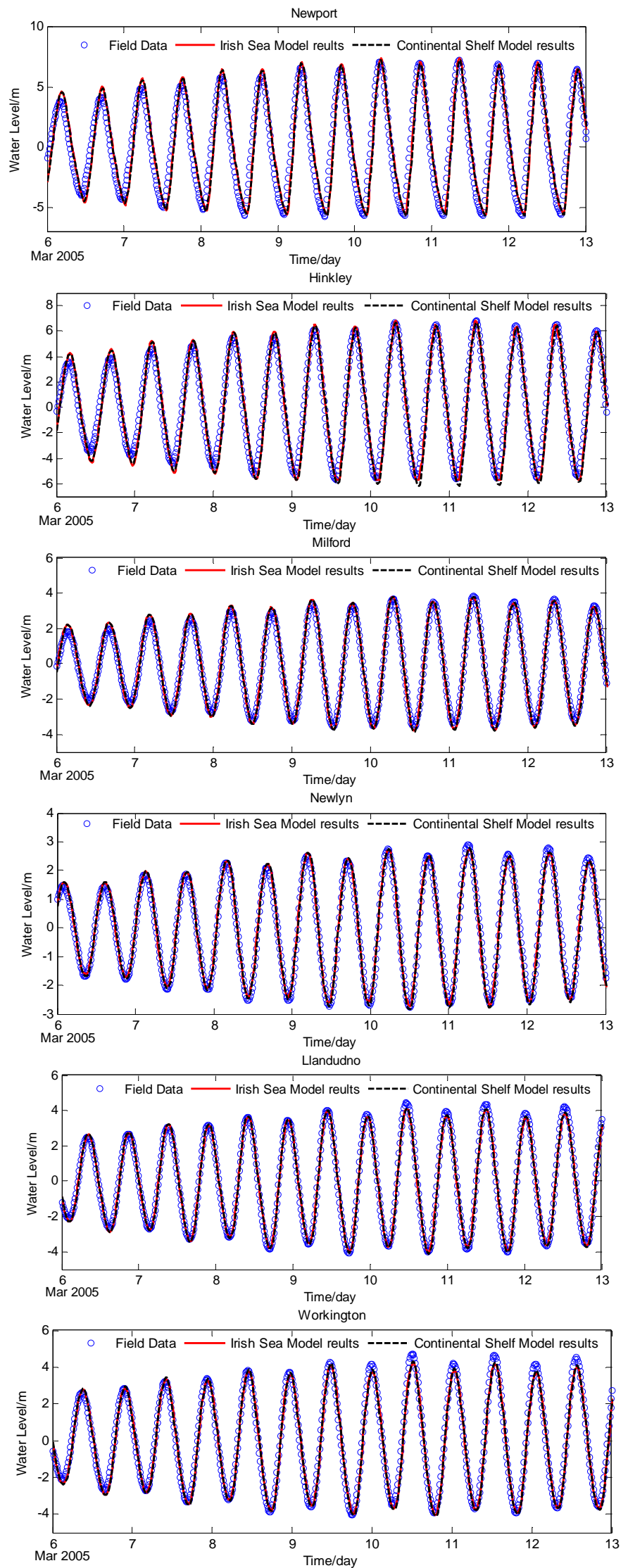

Fig. 2. Comparisons between predicted and observed water levels 

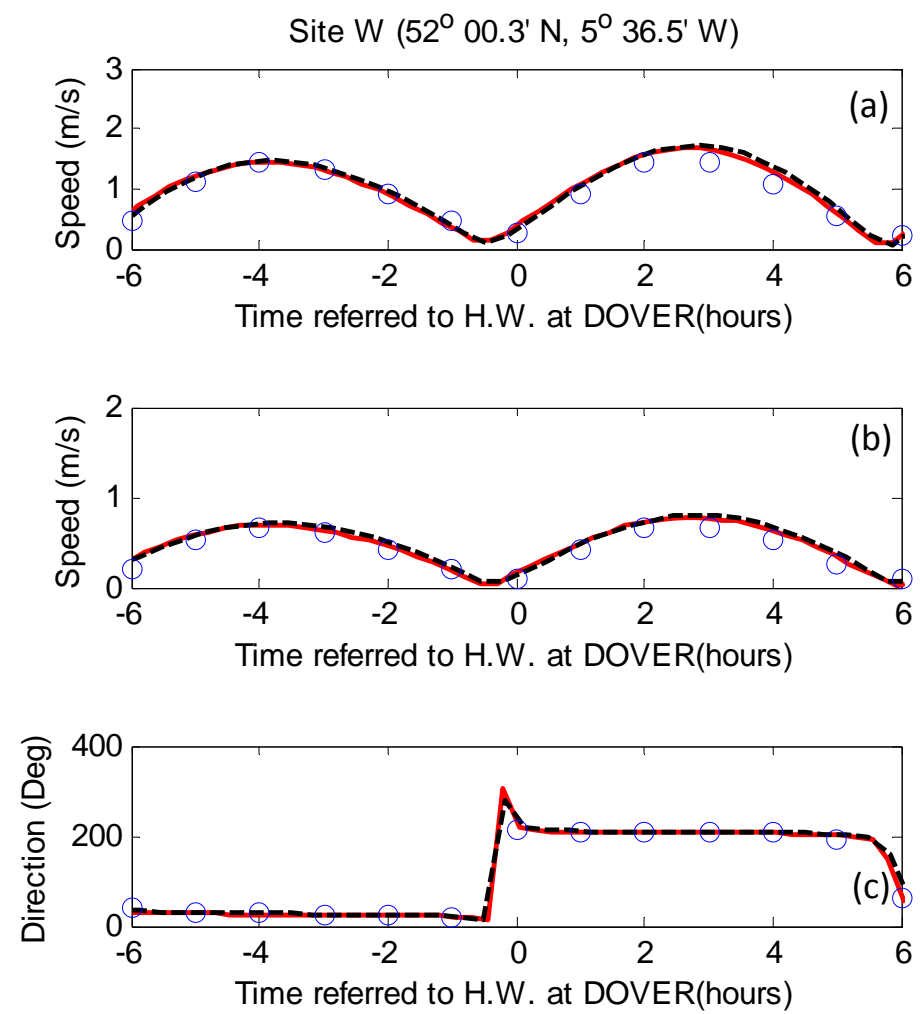

Fig. 3. Comparisons between observed and predicted current speed: 


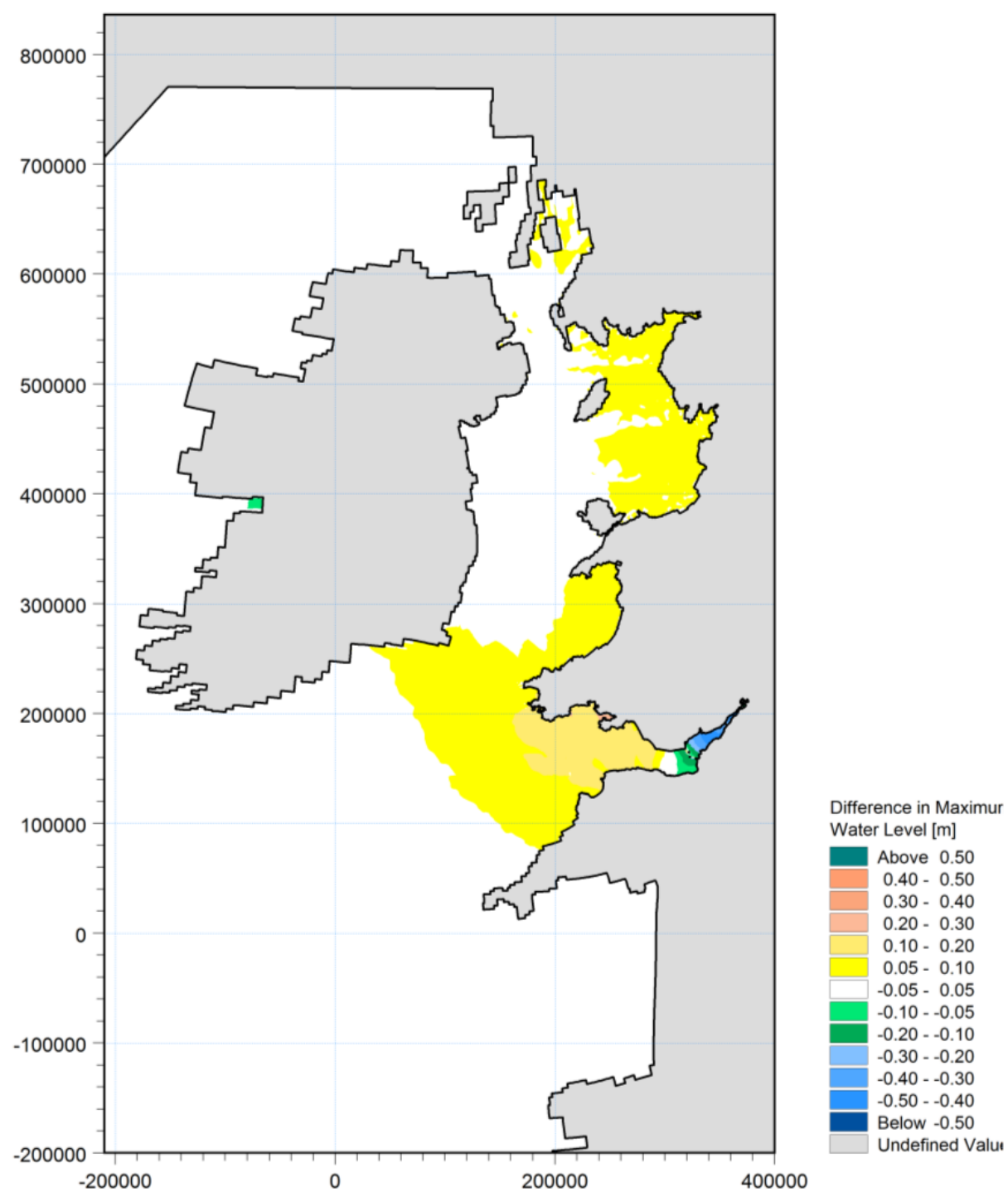

Fig. 4. Difference in predicted maximum water level between Case $C 1$ and Case $C 2$ 


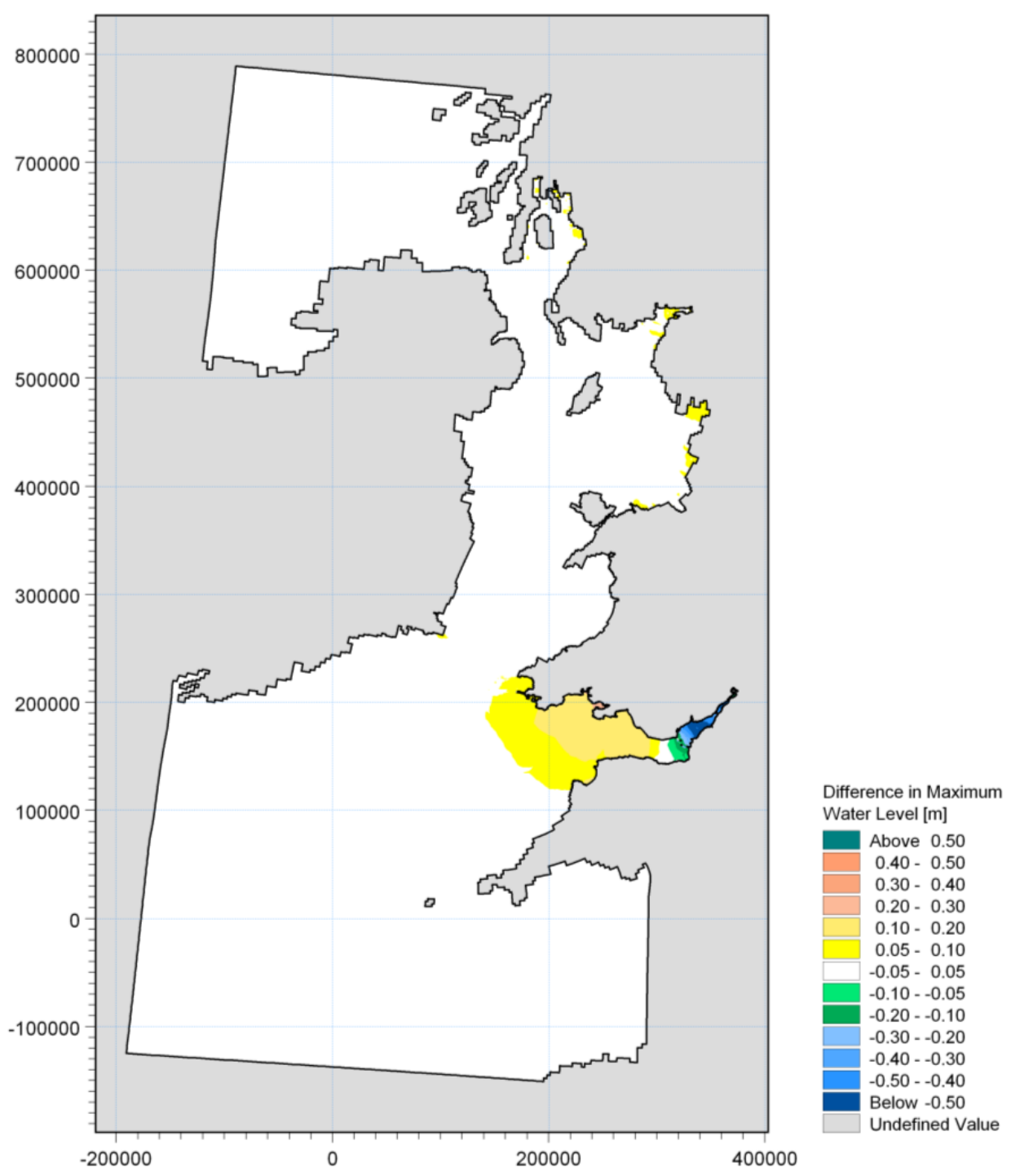

Fig 5. Differences in predicted maximum water levels between Case I1 and Case I2 451 


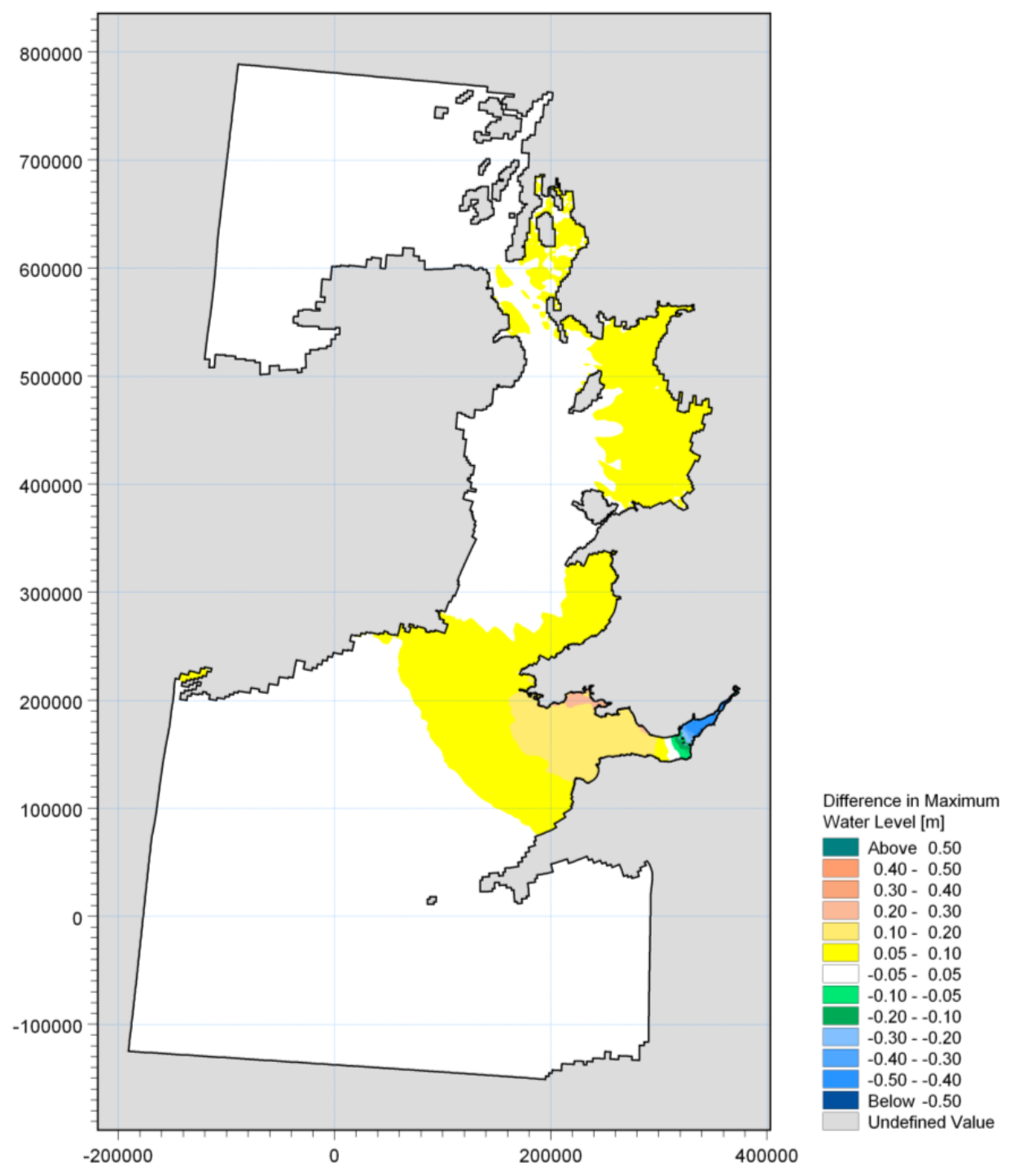

Fig. 6. Differences in predicted maximum water levels between Case I1 and Case I3 453 

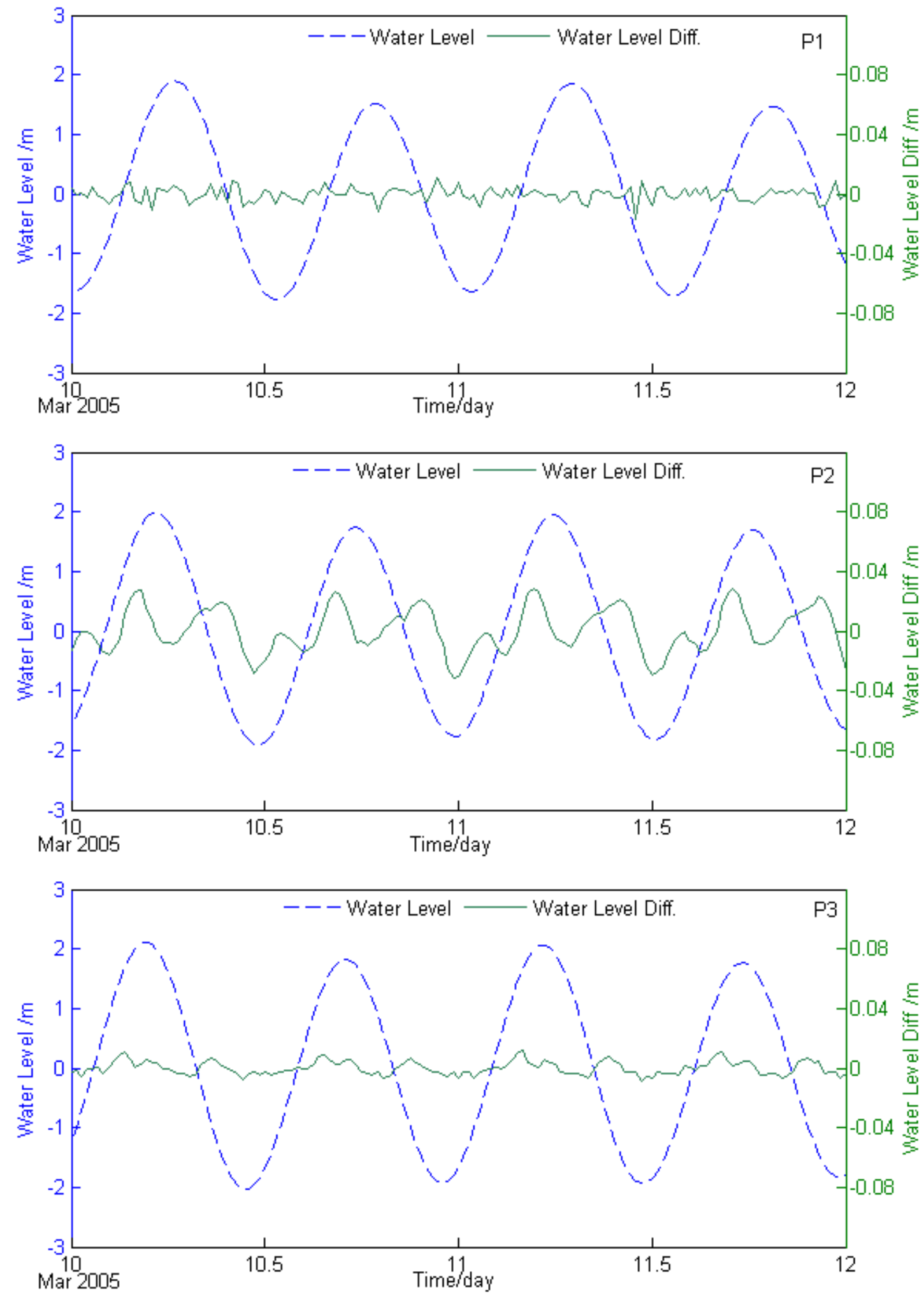

Fig. 7. Time series of water level and water level differences between Cases $C 1$ and $C 2$ at locations P1,P2 and P3 as located by triangles in Fig.2 

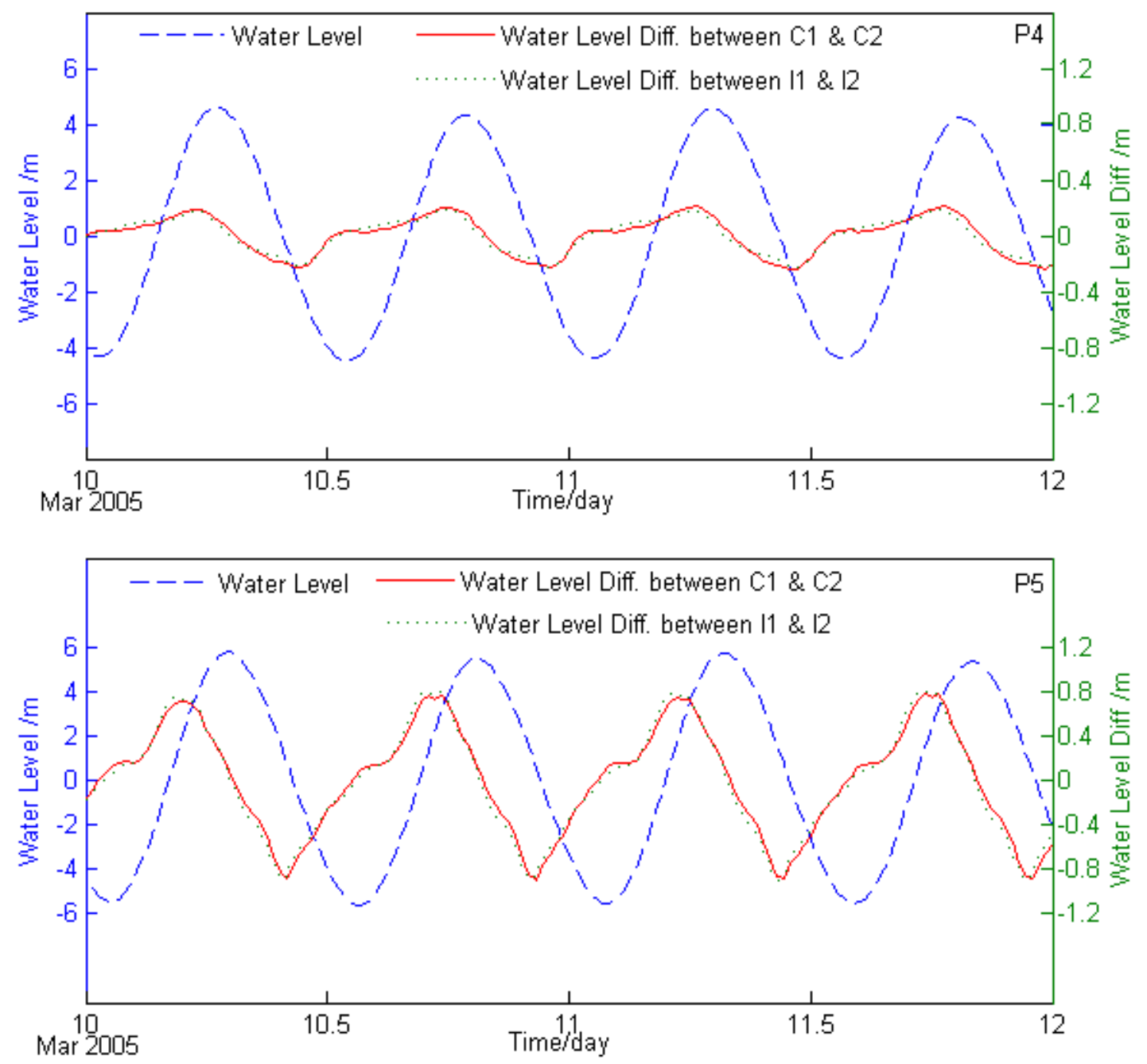

Fig. 8. Time series of predicted water levels and water level differences at locations: P4 and P5 

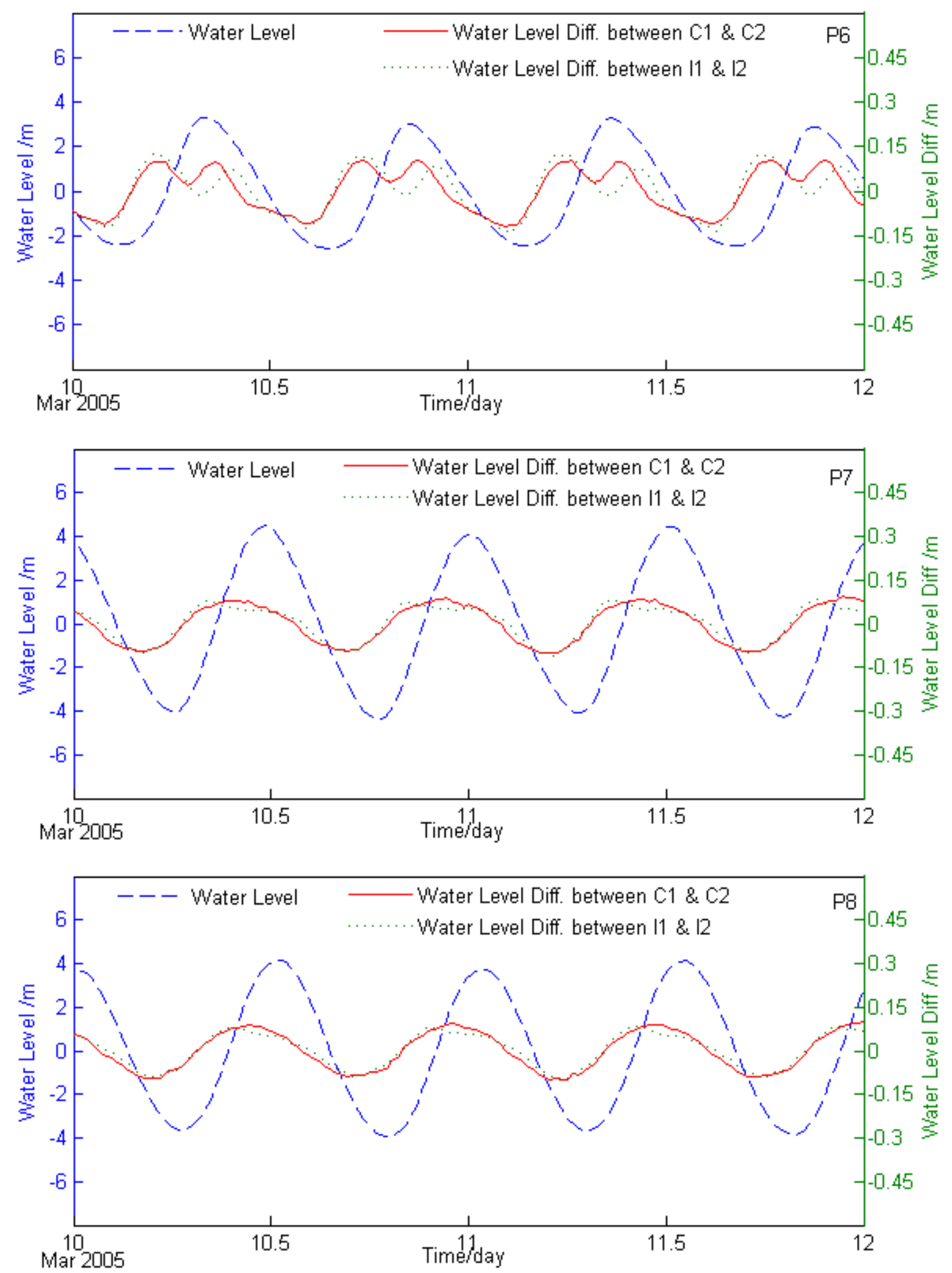

Fig. 9. Time series of predicted water levels and water level differences at locations P6, P7 and P8 


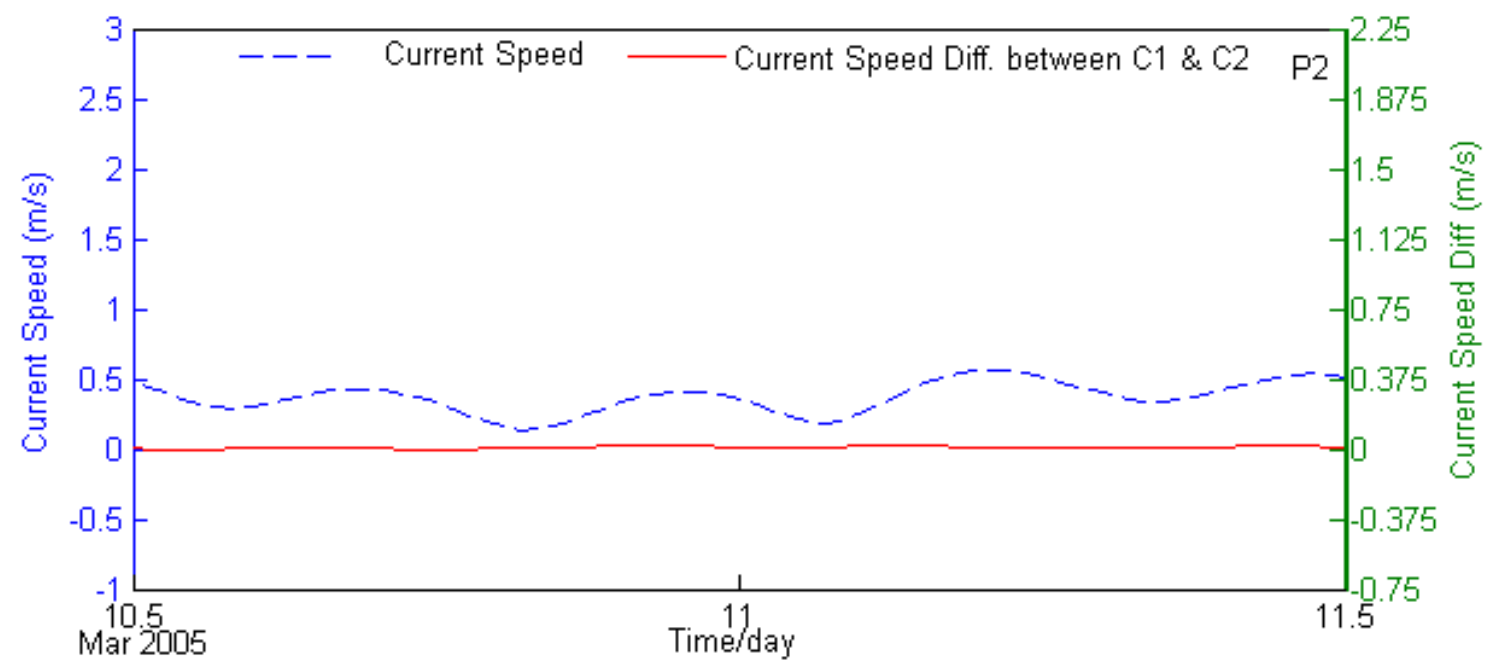

471
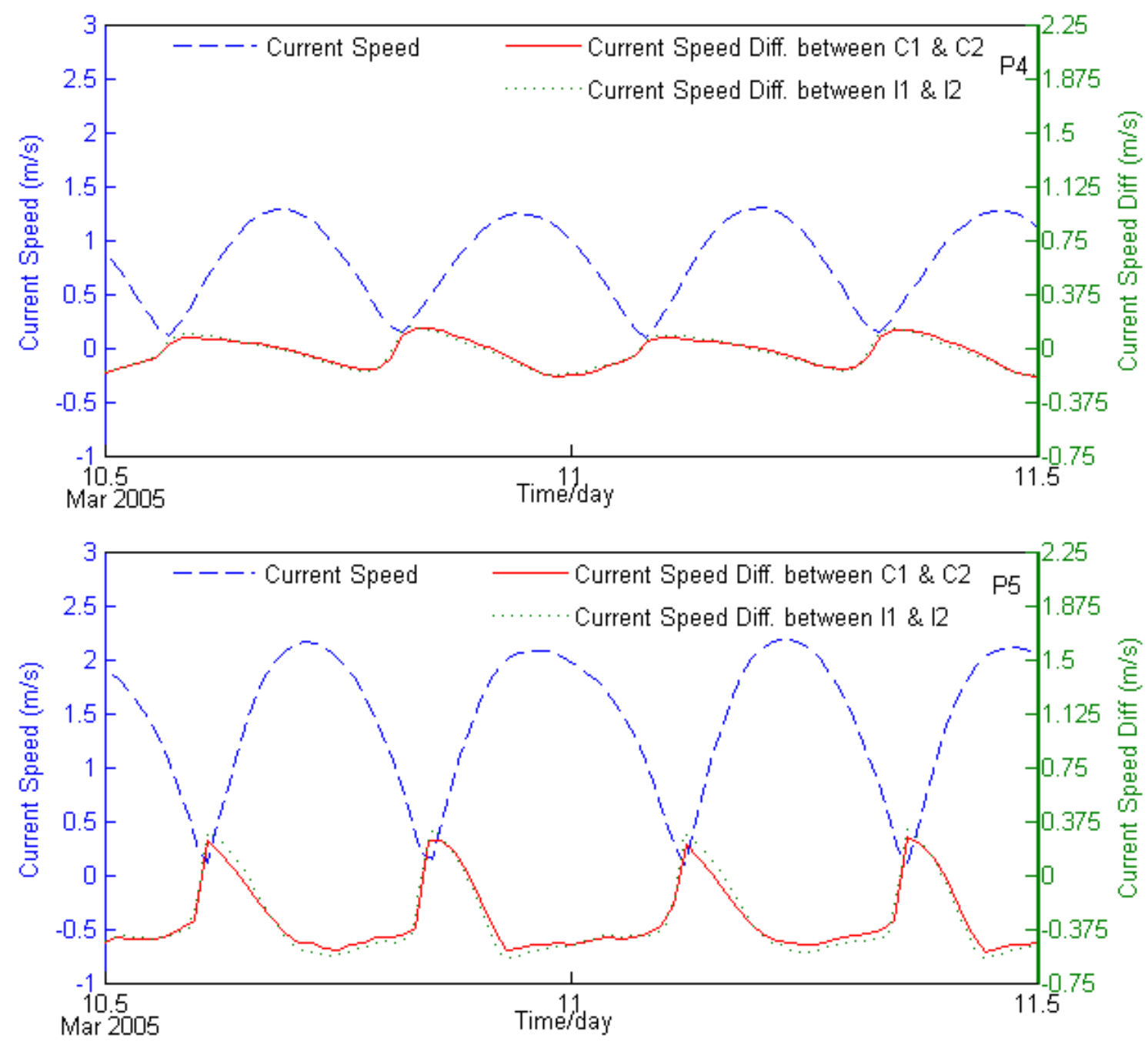

Fig. 10. Time series of predicted tidal current speeds and differences at P2, P4 and P5 